Michael Höttemann

Verdrängter Antisemitismus

Kulturen der Gesellschaft | Band 51 
Michael Höttemann (Dr. phil.), geb. 1981, lebt in Darmstadt. Der Soziologe promovierte an der Philipps-Universität Marburg und war wissenschaftlicher Mitarbeiter am Zentrum für Konfliktforschung. Er ist Mitglied des Villigster Forschungsforums zu Nationalsozialismus, Rassismus und Antisemitismus e.V. 
Michael Höttemann

\section{Verdrängter Antisemitismus}

Eine empirisch fundierte Entwicklung des Begriffs der Abwehr als soziale Handlung 
Förderung durch die Stiftung Zeitlehren.

Förderung durch die Universitätsstiftung der Philipps-Universität Marburg.

Förderung durch die Carl und Charlotte Schott-Stiftung an der Phillips-Universität Marburg.

Förderung durch die Brockhaus-Stiftung.

Unterstützt durch ein Stipendium des Evangelischen Studienwerks e.V.

Dissertation der Philipps-Universität Marburg

\section{Bibliografische Information der Deutschen Nationalbibliothek}

Die Deutsche Nationalbibliothek verzeichnet diese Publikation in der Deutschen Nationalbibliografie; detaillierte bibliografische Daten sind im Internet über http://dnb.d-nb.de abrufbar.

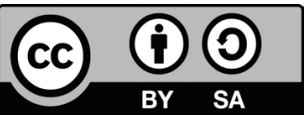

Dieses Werk ist lizenziert unter der Creative Commons Attribution-ShareAlike 4.0 Lizenz (BY-SA). Diese Lizenz erlaubt unter Voraussetzung der Namensnennung des Urhebers die Bearbeitung, Vervielfältigung und Verbreitung des Materials in jedem Format oder Medium für beliebige Zwecke, auch kommerziell, sofern der neu entstandene Text unter derselben Lizenz wie das Original verbreitet wird. (Lizenz-Text:

https://creativecommons.org/licenses/by-sa/4.o/deed.de)

Die Bedingungen der Creative-Commons-Lizenz gelten nur für Originalmaterial. Die Wiederverwendung von Material aus anderen Quellen (gekennzeichnet mit Quellenangabe) wie z.B. Schaubilder, Abbildungen, Fotos und Textauszüge erfordert ggf. weitere Nutzungsgenehmigungen durch den jeweiligen Rechteinhaber.

\section{Erschienen 2022 im transcript Verlag, Bielefeld (๑) Michael Höttemann}

Umschlaggestaltung: Kordula Röckenhaus, Bielefeld Druck: Majuskel Medienproduktion $\mathrm{GmbH}$, Wetzlar

Print-ISBN 978-3-8376-5932-0

PDF-ISBN 978-3-8394-5932-4

https://doi.org/10.14361/9783839459324

Buchreihen-ISSN: 2703-0040

Buchreihen-eISSN: 2703-0059

Gedruckt auf alterungsbeständigem Papier mit chlorfrei gebleichtem Zellstoff. Besuchen Sie uns im Internet: https://www.transcript-verlag.de Unsere aktuelle Vorschau finden Sie unter www.transcript-verlag.de/vorschau-download 